track as the front wheels in a turn. As well as allowing a tight turning circle, this arrangement reduces the power required for steering over the Moon's dusty surface. With a cruising speed of $9 \cdot 2$ miles per houron a smooth surface-and a range of 66 miles it looks as if the full use of the vehicle will depend on a substantial increase in the length of time an astronaut can rely on his life-support system.

Precision of landing on the Moon's surface boils down to the need for an accurate knowledge of the position of the lunar module when the descent to the surface begins. The crew will no doubt take pains to avoid disturbing their orbit prior to this stage of the mission. The dumping of water, which is thought to have contributed to the large error last time, is going to be avoided for eight hours or so before the landing. Separation of the lunar module from the command module will be done as gently as possible and with the axis of the combined spacecraft aligned along a lunar radius vector. This should avoid any unknown perturbations in the velocity of the lunar module in the direction in which it is travelling. And the pirouette by the lunar module so that the pilot of the command module can make sure everything looks all right will be shorter than last time; small changes in the orbit of the lunar module are believed to have crept in at this stage of the Apollo 11 mission contributing to the error at the landing site.

If all this works, Conrad and Bean will touch down on November 19 within about 1,120 feet of Surveyor 3 at latitude $-2 \cdot 98^{\circ}$, longitude $-23 \cdot 39^{\circ}$. If necessary, however, this could be up to 3,300 feet from the lunar module. It is during the second moonwalk that the samples will be collected, and the same methods will be used as in July. About $130 \mathrm{lb}$ of material is to be collected, compared with the $48 \mathrm{lb}$ brought back by Apollo 11, and will include core samples down to 10 inches beneath the surface and material from a 6-inch deep trench which the astronauts will scoop out.

\section{FLUID POWER}

\section{Boost for hydrostatics}

THe importance of strengthening research on fluid power was the message of Dr Ermest Davies, the recently appointed Joint Parliamentary Secretary at the Ministry of Technology, when he opened the new Bramah fluid power laboratory at the National Engineering Laboratory at East Kilbride last week. He was optimistic about the hydrostatically controlled car. "One of the most exciting prospects for the future," he said, "is a car with a single pedal control, the drive going through hydrostatic transmission in place of the conventional clutch, gear box and differential. The National Engineering Laboratory is now working side by side with British Leyland to sco how these ideas can best be exploited commercially."

Hydrostatic transmission systems differ from hydraulic systems in that the power is transmitted as internal or potential energy within the fluid rather than as kinetic energy. This has several advantages. For one thing, it is possible to have outlets that can operate either by suction or ejection, which makes it possible to combine the action of a motor and a brake in a single system. The laboratory has found the hydrostatic transmission system useful for producing high torque at low speeds. Two successful applications have been in contractors' dumper trucks and for the drive of a 50 foot radar aerial weighing about 10 tons.

The Bramah building is destined to be a focus of research in both the pure and applied sides of fluid power. Built at a cost of $£ 400,000$, it will house projects to study hydrostatic pumps, motors and other components of fluid systems and to follow through the applications to machine tools, motor vehicles, ships and a variety of industrial equipment. The outlook for machine tools operating with hydrostatic transmissions is thought to be particularly bright, especially for the new type of lathe in which the work-piece is used as the tool.

One of the chief factors preventing the more widespread introduction of fluid power systems is believed to be some lack of confidence in replacing proven mechanical systems by devices whose value has been proved only on paper. This seems to be particularly true in the motor industry, although the collaboration between NEL and British Leyland offers a way out of the vicious circle. The NEL also has high hopes of marine uses for its motors with radial pistons, whose efficiency at low speeds offers a realistic alternative for the tug.

At present, fluid power research takes up about 12 per cent of the budget of the NEL, which has an annual expenditure of about $£ 2 \cdot 25$ million.

\section{WHITE FISHERIES \\ More Money for Fish}

ThE White Fish Authority in its latest research and development report has once again emphasized the fact that it wants very much more money for this work for which it currently has little more than $£ 400,000$ to spend each year. Half of this sum comes from its own funds and half from the Treasury via the Ministry of Agriculture. Even to outsiders, this sum seems too small for the range of development work the authority wants to do for the fishing industry. This includes such wide ranging activities as research on the mechanization of fishing operations and fishing aids, the handling, processing and distribution of fish and the practicalities of marine fish farming (see Nature, 224, 205; 1969). The authority finds it difficult to cope with many individual projects needing annual

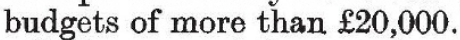

It has nonetheless made some significant progress recently with such things as boxing and transferring catches at sea, and the development of a gutting machine.

While such developments will, of course, help the economics of the industry and the safety of the crews, the authority's other objective is more satisfied customers. To improve the image of fresh and frozen fish among housewives, the authority has been experimenting with sales of prepackaged chilled wet fish in supermarkets and with new fish products such as canned soups, fish potato chips, and fish crisps. In particular the authority has been directing its efforts at schoolchildren in the past two years. The problcm is that the Department of Education and Science recommends that children should be served only two fish meals out of twenty in school. If four meals a month became the recommended level, the authority claims that the British fishing industry could benefit by another $£ 2$ million a year. But would schoolchildren 
eat fish twice a week at school ? Five trials, involving forty schools and 13,000 children, has indeed shown (see Fish in School Meals published by the authority) that children like fish as much as meat, provided it is of reasonable quality and attractively served. The surveys carried out by the authority and supported by evidence obtained by the Ministry of Technology's Torry Research Station also showed that fish is cheaper than meat and nutritionally just as good.

The authority now hopes to persuade the DES to revise its school meal recommendations, and the local education authorities to adopt purchase and handling specifications to control the quality of fish for schools.

\section{SCIENCE FAIR}

\section{World Series in School Science}

THE International Science Fair (ISF) programme is now in its twenty-first year and growing fast. Every year, more and more American students in the tenth, eleventh and twelfth grades at secondary schools answer its challenge to "try doing your own thing in science", which means finding a scientific project to study, either in or out of school, and exhibiting the results of their endeavours in the school science fair. From this beginning, the aspiring young scientist may find that his project has been selected for exhibition in one of 200 regional fairs, where it will be judged against strong competition for a place in the International Science Fair. Here, the 400 exhibitors will have the opportunity to win one of the many awards donated by more than thirty national scientific organizations and federal services, but, as Science Service, the non-profitmaking organization for the popularization of science which runs ISF, points out, the main award is the opportunity to gain a place in the final and to achieve the recognition among the scientific community which this brings. Consequently, every finalist receives an ISF Medal Award-"a rainbow ribboned silver medal with a gold science emblem".

The selection process for the ISF involves thousands of school fairs and millions of students, teachers, scientists, parents and visitors, and this certainly helps to popularize science in secondary schools. Moreover, the standard of the entries is usually very high, and sometimes they involve complex subjects; for example, last year's winners included projects on storing information in crystals, building synthetic peptides and an investigation into a possible relationship between mathematical formulae and marine mollusc growth. However, the International Science Fair is more like the "World Series" of science fairs, because its entrants are predominantly Americanout of forty-two major prizewinners last year, only one was not American-and it seems that the twenty-first International Science Fair, which will be held in Baltimore in May 1970, will follow a similar pattern.

\section{CHEMISTRY PRIZE}

\section{Conformation Analysis Honoured}

THIs year's Nobel Prize for Chemistry has gone to Professor Derek H. R. Barton at Imperial College, London, and Professor Odd Hassel, the distinguished Norwegian theoretical chemist, for their work "to develop and apply the concept of conformation in chemistry". The $£ 30,000$ award relates to the research done by Professor Hassel in the 1940s on the molecular structure of cyclohexane derivatives and Professor Barton's extension of the ideas of conformation to complex organic structures.

Dr Hassel uscd the techniques of electron diffraction, under what Professor Barton describes as incredibly difficult circumstances during the war, to make threedimensional images of simple molecules which he saw existed in preferred conformations. This helped him to realize that the analysis of the conformation of organic molecules could help to explain their chemical reactions and, in fact, could be used to predict the way they would react. Since then, conformation analysis has become a powerful tool in predicting the configuration of natural substances such as steroids, alkaloids and terpenes, in the analysis of reaction mechanisms and in the synthesis of organic molecules. One important application of this type of analysis is in drug research to find the part of a molecule at which combination with other substances takes place.

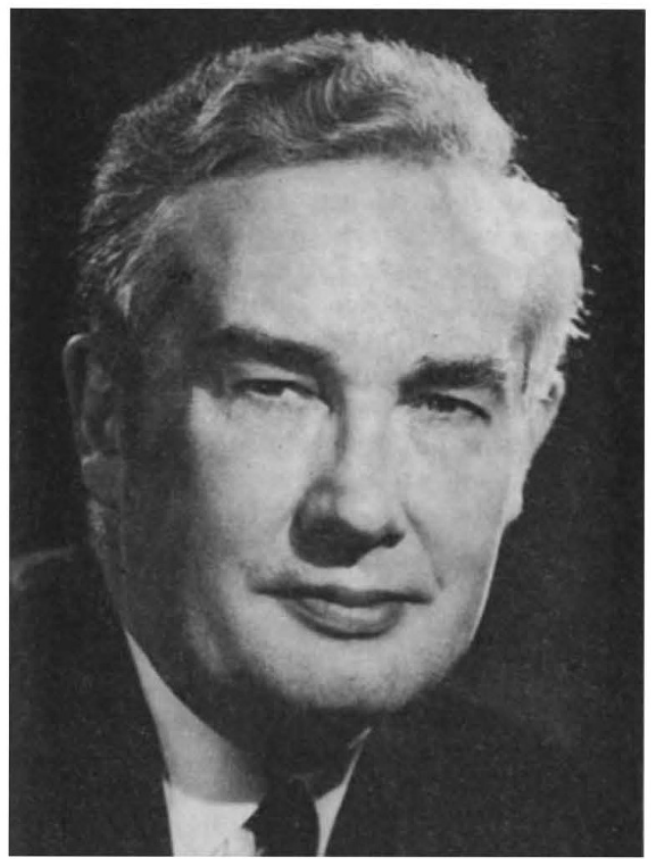

Since his original work on three-dimensional analysis, Professor Barton has gone on to study the paths by which natural substances are manufactured by plants and moulds. One of his chief interests now is the synthesis of biologically important steroid and alkaloid molecules.

Professor Hassel, who is 72, was a lecturer and later professor of physical chemistry at Oslo University from 1926 to 1964. Professor Barton, now 51, has been interested in steroid chemistry since he was a student at Imperial College. He followed up Hassel's work during a period when he was a visiting professor at Harvard, and he returned to Imperial College twelve years later as professor of organic chemistry.

\section{PHYSICS PRIZE}

\section{No Sirangeness Here}

The award of the Nobel Prize for Physics to Professor Murray Gell-Mann, the man who put forward the 